\title{
Absence of CCND1 gene amplification in breast tumours of BRCA1 mutation carriers
}

\author{
S A J Vaziri, R R Tubbs, G Darlington, G Casey
}

\begin{abstract}
BackgroundlAims-It was recently reported that significantly fewer breast tumours of BRCA1 mutation carriers overexpressed cyclin D1 and HER2 protein than tumours of age matched breast cancer cases unselected for family history. This study aimed to examine the genetic basis of this reduction by determining the frequency of tumours within this cohort showing DNA amplification of these genes.

Methods-Paraffin wax embedded sections of breast tumours from BRCA1 mutation carriers and age, grade, histological type, and tumour size matched non-familial controls that had previously been stained for cyclin D1 and HER2 protein overexpression were analysed for CCND1 and HER2 gene amplification using fluorescence in situ hybridisation. Results-CCND1 amplification was detected in none of the 30 tumours of the BRCA1 mutation carriers and in 19 of 74 tumours of the matched controls. Of those samples previously determined to overexpress the HER2 protein, HER2 amplification was detected in one of three tumours from BRCA1 mutation carriers and in 13 of 17 tumours of the age matched nonfamilial cases.

Conclusion-None of the tumours of BRCA1 mutation carriers showed CCND1 amplification and only one tumour showed HER2 amplification. In contrast, a large proportion of cyclin D1 and HER2 overexpression in tumours of non-familial breast cancer cases could be accounted for by amplification of these genes. These data suggest that breast tumorigenesis in BRCA1 mutation carriers occurs by a molecular mechanism distinct from that of age matched non-familial cases. (f Clin Pathol: Mol Pathol 2001;54:259-263)
\end{abstract}

Keywords: CCND1; HER2; BRCA1

Department of Clinica Pathology, Cleveland Clinic Foundation R R Tubbs

Department of Mathematics and

Statistics, University of Guelph, Guelph,

Ontario, N1G-2X5, Canada

G Darlington

Correspondence to: Dr Casey

caseyg@ccf.org

Accepted for publication 17 April 2001 distinct molecular immunophenotype of tumours of BRCA1 mutation carriers was influenced by age at diagnosis. ${ }^{11 a}$ Significantly fewer tumours of BRCA1 mutation carriers diagnosed before the age of 50 years expressed cyclin D1 (40\%) or HER2 (10\%) compared with tumours of age-matched, non-familial breast cancer controls ( $82 \%$ and $33 \%$, respectively). ${ }^{11 a}$ No significant difference in the frequency of staining of these markers was found in tumours of carriers and controls diagnosed at age 50 years or later.

Cyclin D1 is a cell cycle regulatory protein, and protein overexpression has been reported in $42-80 \%$ of primary breast tumours ${ }^{11-14}$ and breast cancer cell lines. ${ }^{12}$ The CCND1 (cyclin D1) gene maps to chromosome $11 \mathrm{q} 13$, and this region has been reported to be amplified in approximately $30 \%$ of primary breast tumours, ${ }^{13} 15$ and may be associated with poor survival. ${ }^{14}{ }^{16}$ Although a significant reduction in the number of tumours of BRCA1 mutation carriers that overexpress cyclin D1 compared with those of non-familial controls has been reported, ${ }^{11}{ }^{11 a}$ the frequency of CCND1 amplification in breast tumours of BRCA1 mutation carriers has not been assessed.

HER2 protein expression has been widely reported to occur at a significantly lower frequency in breast tumours of BRCA 1 mutation carriers than in tumours of non-familial cases. ${ }^{111 \text { a } 17}{ }^{18}$ HER2 is a tyrosine kinase receptor whose overexpression in breast tumours is associated with a poor prognosis. ${ }^{19}{ }^{20}$ HER2 protein overexpression is associated with HER2 gene amplification in over $70 \%$ of breast tumours of non-familial cases. ${ }^{21-23}$ However, the frequency of HER2 amplification in breast tumours of BRCA1 mutation carriers is not known.

The aim of this study was to determine the frequency of amplification of the CCND1 and HER2 genes in a series of breast tumours of BRCA1 mutation carriers and age-matched non-familial breast cancer controls, in which the frequency of protein overexpression had been determined previously.

We found that none of the tumours of BRCA1 mutation carriers showed CCND1 amplification and only one of three tumours that had previously been shown to express HER2 protein showed amplification of the HER2 gene. These results suggest that mechanisms other than gene amplification are responsible for cyclin D1 and HER2 protein overexpression in breast tumours of BRCA1 mutation carriers, and reveal a molecular 

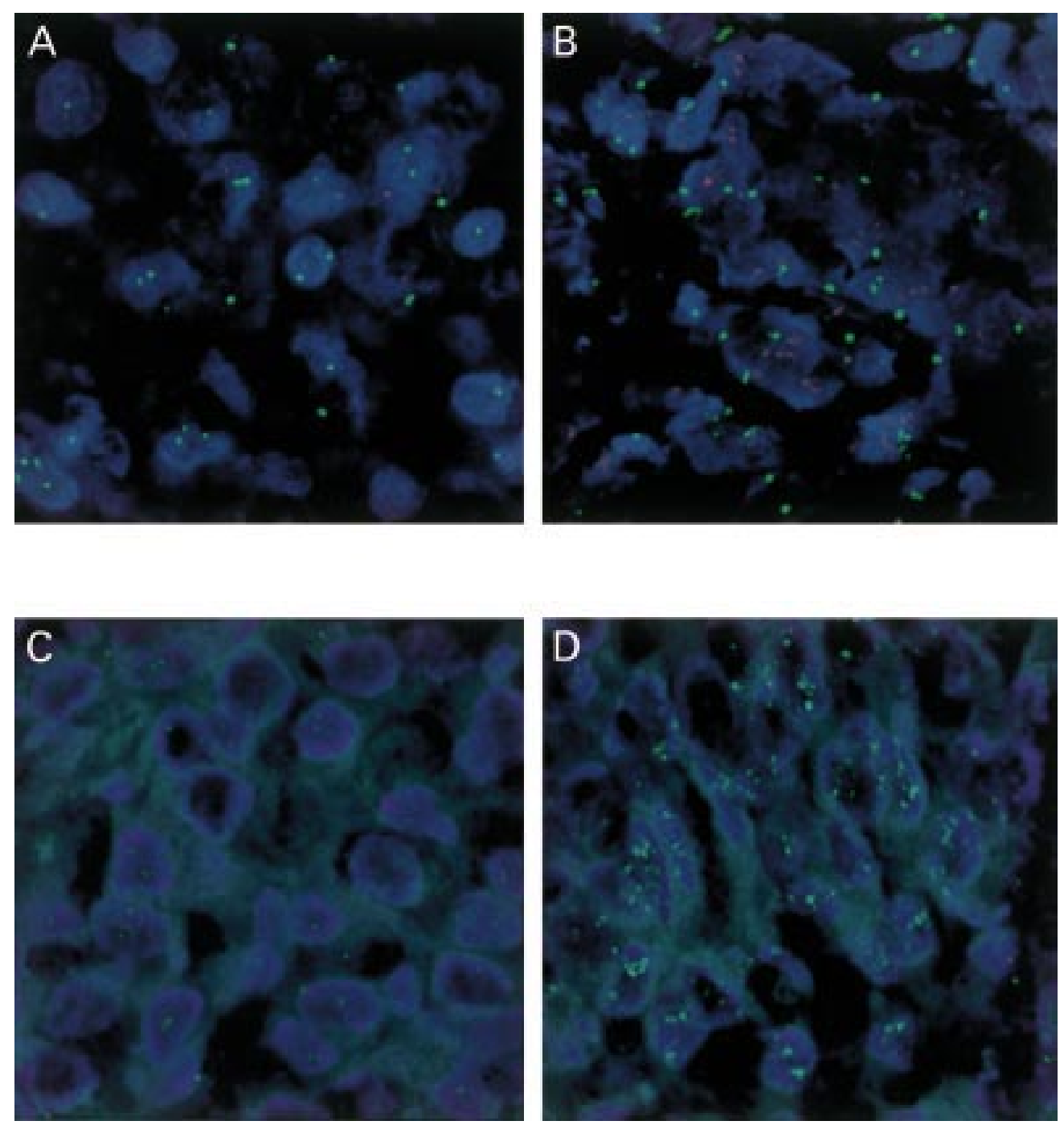

Figure 1 Fluorescence confocal microscopy photomicrographs. Infiltrating ductal carcinoma of breast demonstrating (A) normal CCND1 gene copy (red) and chromosome 11 copy (green), (B) abundant CCND1 gene copy, (C) normal HER2 gene copy (green), (D) abundant HER2 gene copy. Original magnification, $\times 126$.

distinction between tumours of BRCA1 mutation carriers and age matched non-familial breast cancer controls.

\section{Materials and methods}

PATIENTS

Patients with hereditary breast cancer were recruited through the familial cancer registry of the Cleveland Clinic Foundation. BRCA1 mutation carrier status was determined in affected probands with a cancer family history, and confirmed in tumour tissue of affected relatives. ${ }^{24}{ }^{25}$ Written informed consent was obtained from all subjects. The study protocol was approved by the institutional review board of the Cleveland Clinic Foundation.

Tumours from 30 BRCA1 mutation carriers were included in our study. The study population comprised 18 patients with BRCA1 185 del AG, two with BRCA1 5385 ins C, one with BRCA1 5382 ins C, one with BRCA1 3875 del 4, four with BRCA1 C1806T TER, one with BRCA1 C3508G TER, one with BRCA1 2530 del AG, and two with BRCA1 IVS $15-1 \mathrm{G} \rightarrow \mathrm{A}$ mutations.
Controls were patients with breast cancer identified through the tumour registry of the Cleveland Clinic Foundation who were unselected for cancer family history. Controls were matched to each hereditary case based on age at diagnosis ( \pm 5 years), histological type, tumour grade, and tumour size. A total of 74 matched patients with breast cancer unselected for family history were identified and included in our study. Case to control matching was as follows: 16 cases were matched to three controls; 12 cases were matched to two controls; and two cases were matched to one control each. The two BRCA1 mutation carriers who were matched to one control only had early onset medullary cancer and few candidate control matches could be identified in the tumour registry. Clinical features of cases and controls have been described previously. ${ }^{11 a}$ Briefly, mean (SD) age of disease onset was 47.2 (17.9) years for the cases and 46.9 (16.7) years for the controls. The distribution frequency of tumour grade among the BRCA1 cases and controls, respectively, was as follows: $51.6 \%$ and $49.4 \%$ grade $3 ; 29.0 \%$ and $30.9 \%$ 
Table 1 Comparison of gene amplification between patients with BRCA1 mutations and matched patients with breast cancer unselected for family history

\begin{tabular}{llll}
\hline Marker & $\begin{array}{l}\text { BRCA1 } \\
\text { mutation cases }\end{array}$ & $\begin{array}{l}\text { Non-familial } \\
\text { controls }\end{array}$ & p Values \\
\hline CCND1 & $0 / 30$ & $19 / 74$ & 0.001 \\
HER2 & $1 / 3$ & $13 / 17$ & 0.20 \\
\hline
\end{tabular}

HER2 amplification data were captured only for samples that were previously identified as overexpressing HER2 protein. $\mathrm{p}$ Values were determined using the two tailed Fisher's exact test.

grade 2 ; and $19.3 \%$ and $19.8 \%$ grade 1 . Most of the tumours $(74.2 \%$ of the cases; $81.5 \%$ of the controls) were intraductal or lobular ( $16.1 \%$ of the cases; $13.6 \%$ of the controls). Mean (SD) tumour size was $2.49(1.93) \mathrm{cm}$ for the cases and $2.40(1.53) \mathrm{cm}$ for the controls.

\section{FLUORESCENCE IN SITU HYBRIDISATION (FISH) CCND1}

FISH was performed on $4 \mu \mathrm{m}$ thick paraffin wax embedded tissue sections of breast tumour tissue as described previously. ${ }^{23}$ After dewaxing, cell conditioning using target retrieval solution (Dako, Carpinteria, California, USA), and proteinase $\mathrm{K}$ treatment, each section was hybridised with $10 \mu \mathrm{l}$ of a dual labelled probe containing a spectrum green label for the centromeric region of chromosome 11 (CEP 11) and a spectrum orange label for the CCND1 locus (Vysis, Downers Grove, Illinois, USA) and coverslipped. The sections were incubated at $90^{\circ} \mathrm{C}$ for six minutes then overnight at $37^{\circ} \mathrm{C}$ in a humidified chamber. Post hybridisation washes were performed using $2 \times$ saline sodium citrate (SSC) at room temperature for five minutes, $2 \times$ SSC for three minutes at $72^{\circ} \mathrm{C}$, and phosphate buffered saline (PBS) $/ 0.1 \%$ Tween 20 ( $\mathrm{pH} \mathrm{7.4)} \mathrm{for} \mathrm{five} \mathrm{minutes} \mathrm{and} \mathrm{the}$ sections were counterstained with $15 \mu \mathrm{l}$ of DAPI $(0.1 \mu \mathrm{l} / \mathrm{ml})$ in antifade solution (Ventana, Tucson, Arizona, USA). Signals were visualised using an Olympus BX40 fluorescence microscope (Olympus America, Melville, New York, USA) with three band pass filters. Two representative fields were identified in the area preselected for probe application and gene copy numbers were counted in 40 nuclei, 20 in each of the two representative fields. Tumours with a higher number of CCND1 signals compared with CEP11 signals were classified as demonstrating CCND1 amplification (fig $1 \mathrm{~A}, \mathrm{~B}$ ).

\section{HER2}

HER2 amplification was detected using an indirect digoxigenin labelled antibody protocol. ${ }^{25 a}$ After dewaxing, cell conditioning using target retrieval solution (Dako) and proteinase $\mathrm{K}$ treatment, $10 \mu \mathrm{l}$ of digoxigenin labelled HER2 probe (Zymed, South San Francisco, California, USA) was applied to all sections, which were then coverslipped. The sections were incubated as described above. Post hybridisation washes were performed using $2 \times$ SSC for five minutes at room temperature, $0.5 \times \mathrm{SSC}$ for five minutes at $72^{\circ} \mathrm{C}$, and $\mathrm{PBS} / 0.1 \%$ Tween $20(\mathrm{pH} 7.4)$ at room temperature for five minutes. Fluorescein isothiocyanate (FITC) labelled antidigoxigenin antibody (1/50; Roche, Indianapolis, Indiana, USA) prepared in PBS ( $\mathrm{pH} 7.4$ ) containing $0.5 \%$ bovine serum albumin was applied to each slide and incubated for 30 minutes in a humidified chamber at room temperature. The sections were then washed three times in PBS/ $0.1 \%$ Tween 20 for five minutes each and counterstained with DAPI as described above. Two representative fields were identified in the area preselected for probe application and the gene copy number was counted for a total of 40 nuclei, 20 in each of the two representative fields. HER2 gene copy amplification was classified as present if the gene copy number was $\geqslant 5$ (fig $1 \mathrm{C}, \mathrm{D}$ ).

\section{STATISTICAL METHODS}

Fisher's exact test was used for case-control studies involving variable numbers of controls to compare the BRCA1 mutation carrier cases and non-familial breast cancer controls with respect to CCND1 and HER2 amplification frequencies. ${ }^{26}$

\section{Results}

We found previously that significantly fewer breast tumours of BRCA1 mutation carriers (16 of 30) than tumours of age matched non-familial breast cancer controls (67 of 78) overexpressed cyclin D1 protein. ${ }^{11 a}$ In our present study, we evaluated the molecular basis of cyclin D1 overexpression in these tumours. We found that none of 30 tumours from BRCA1 mutation carriers showed CCND1 gene amplification, whereas 19 of 74 tumours from non-familial breast cancer controls showed CCND1 gene amplification (table 1; $\mathrm{p}=0.001$ ). In all cases where CCND1 gene amplification occurred, tumours stained positive for cyclin D1 protein overexpression.

We also found previously that the frequency of tumours overexpressing cyclin D1 protein in this series was influenced by age at diagnosis in both BRCA1 mutation carriers and matched non-familial breast cancer controls. A difference in the frequency of tumours staining positive for cyclin D1 between BRCA1 mutation carriers and matched non-familial breast cancer controls was observed only in tumours of patients diagnosed before the age of 50 years. ${ }^{11 a}$ In our present study, a significant difference in the frequency of tumours with CCND1 amplification was seen only between BRCA1 mutation carriers and matched controls diagnosed under the age of 50 years (table $2 ; \mathrm{p}=0.002$ ). No significant difference in the frequency of CCND1 amplification was seen in those patients diagnosed at 50 years of age or older (table $2 ; \mathrm{p}=1.0$ ). These observations are attributed to age related differences in CCND1 amplification frequencies in tumours of nonfamilial breast cancer controls. We found that a significantly higher frequency of tumours of non-familial breast cancer controls diagnosed before the age of 50 years demonstrated CCND1 amplification compared with tumours of controls diagnosed at age 50 years or older (table $3 ; p=0.01$ ). These data imply that CCND1 amplification occurs infrequently in 
Table 2 Comparison of gene amplification in tumours from patients with BRCA1 mutations and patients with breast cancer unselected for family history stratified by age

\begin{tabular}{lllll}
\hline Marker & Age (years) & $\begin{array}{l}\text { BRCA1 mutation } \\
\text { cases }\end{array}$ & $\begin{array}{l}\text { Non-familial } \\
\text { controls }\end{array}$ & p Values \\
\hline CCND1 & $<50$ & $0 / 20$ & $17 / 48$ & 0.002 \\
HER2 & $\geqslant 50$ & $0 / 10$ & $2 / 26$ & 1.0 \\
& $<50$ & $0 / 2$ & $13 / 17$ & 0.09 \\
& $\geqslant 50$ & $1 / 1$ & $0 / 0$ & ND \\
\hline
\end{tabular}

HER2 amplification data were captured only for samples that were previously identified as overexpressing HER2 protein.

$\mathrm{p}$ Values were determined using the two tailed Fisher's exact test.

ND, not determined.
BRCA1 mutation carriers compared with those of matched breast cancer case controls.

We found that none of the tumours of BRCA1 mutation carriers showed CCND1 gene amplification, whereas approximately a quarter of the tumours of the non-familial breast cancer patients showed CCND1 amplification. This frequency in the control breast cancer subjects is similar to that reported elsewhere. $^{1328}$ These data imply that CCND1 amplification is not a mechanism by which cyclin D1 protein overexpression occurs in tumours of BRCA1 mutation carriers. Several genes have been reported to upregulate the transcription of CCND1, including $\mathrm{MYC}^{29}$ HER2, ${ }^{30}$ and the genes encoding $\beta$-catenin ${ }^{31}$ and the hormone estrogen. ${ }^{32}$ In our studies, $\beta$-catenin was expressed at a significantly higher frequency in tumours of BRCA1 mutation carriers than matched breast cancer controls. $^{11 \mathrm{a}}$

We also determined the frequency of HER2 amplification in those tumours that overexpressed HER 2 protein in the original study. We found that HER2 amplification occurred in only three quarters of breast tumours of non-familial breast cancer cases, in agreement with published studies. ${ }^{22} 33$ However, HER2 amplification occurred in only one third of breast tumours of BRCA1 mutation carriers that overexpressed HER2 protein. Unlike cyclin D1 overexpression, published data suggest that most cases of HER2 protein overexpression in tumours of non-familial breast cancer cases can be attributed to amplification of the HER2 gene. ${ }^{34} 35$ Because HER2 transcriptional upregulation has been shown to occur only infrequently in non-familial breast tumours, ${ }^{25 a}{ }^{35}$ these data suggest that the overall reduction in the frequency of HER2 overexpression may be a direct result of the reduction in the frequency of HER2 gene amplification.

Do these results imply that gene amplification is a rare mechanism in tumours of BRCA1 mutation carriers? This seems unlikely because comparative genome hybridisation approaches suggest several distinct genomic loci harbour genes that are amplified in tumours of both BRCA1 and BRCA2 mutation carriers. ${ }^{36}$ In addition, a recent study reported that the MYB oncogene was frequently amplified in tumours of BRCA1 mutation carriers. ${ }^{37}$ It is probable that our data reflect the presence of alternative molecular pathways of tumour development in tumours of BRCA1 mutation carriers compared with non-familial cases.

In summary, our data suggest that the reduced frequency of protein overexpression of cyclin D1 and HER2 in tumours of BRCA1 mutation carriers may be accounted for, at least in part, by the absence of amplification of the CCND1 and HER2 genes in these tumours. These data support the likelihood of distinct pathways of tumorigenesis in tumours of BRCA1 mutation carriers compared with tumours of patients with non-familial breast cancer.

We thank L M Krumroy and J Pettay for technical assistance. the absence of CCND1 gene amplification and a substantial reduction in the frequency of HER2 gene amplification in tumours of 
1 Porter DE, Cohen BB, Wallace MR, et al. Breast cancer incidence, penetrance and survival in probable carriers of BRCA1 gene mutation in families linked to BRCA1 on

chromosome 17q12-21. Br f Surg 1994;81:1512-15.

2 Marcus JN, Watson P, Page DL, et al. Hereditary breast cancer: pathobiology, prognosis, and BRCA1 and BRCA2 gene linkage. Cancer 1996;77:697-709.

3 Eisinger F, Stoppa-Lyonnet D, Longy M, et al. Germ line mutation at BRCA1 affects the histoprognostic grade in hereditary breast cancer. Cancer Res 1996;56:471-4.

4 Karp SE, Tonin PN, Begin LR, et al. Influence of BRCA1 mutations on nuclear grade and estrogen receptor status of breast carcinoma in Ashkenazi Jewish women. Cancer 1997;80:435-41.

5 Breast Cancer Linkage Consortium. Pathology of familial breast cancer: differences between breast cancers in carriers of BRCA1 or BRCA2 mutations and sporadic cases. Breast Cancer Linkage Consortium. Lancet 1997; 349:1505-10.

6 Lakhani SR, Jacquemier J, Sloane JP, et al. Multifactorial analysis of differences between sporadic breast cancers and cancers involving BRCA1 an

7 Armes JE, Egan AJ, Southey MC, et al. The histologic phenotypes of breast carcinoma occurring before age 40 years in women with and without BRCA1 or BRCA2 germline mutations: a population-based study. Cancer 1998;83 2335-45

8 Robson M, Gilewski T, Haas B, et al. BRCA-associated breast cancer in young women. $\mathcal{F}$ Clin Oncol 1998;16:16429.

9 Marcus JN, Watson P, Page DL, et al. Pathology and heredity of breast cancer in younger women. 7 Natl Cancer Inst Monogr 1994:16:23-34.

10 Kollias J, Elston CW, Ellis IO, et al. Early-onset breast cancer-histopathological and prognostic considerations. Brf Cancer 1997;75:1318-23.

11 Armes JE, Trute L, White D, et al. Distinct molecular pathogeneses of early-onset breast cancers in BRCA1 and pathogeneses of early-onset breast cancers in BRCA1 and cer Res 1999;59:2011-17.

11aVaziri SAJ, Krumroy LM, Elson P, et al. Breast tumor pathology and immunophenotype are associated with age of onset of cancer in BRCA1 mutation carriers. Clin Cance Res [In press.]

12 Buckley MF, Sweeney KJ, Hamilton JA, et al. Expression and amplification of cyclin genes in human breast cancer. Oncogene 1993;8:2127-33.

13 Gillett C, Fantl V, Smith R, et al. Amplification and overexpression of cyclin D1 in breast cancer detected by immunohistochemical staining. Cancer Res 1994;54:181217.

14 Kenny FS, Hui R, Musgrove EA, et al. Overexpression of cyclin D1 messenger RNA predicts for poor prognosis in estrogen receptor-positive breast cancer. Clin Cancer Res 1999;5:2069-76.

15 Zhou DJ, Casey G, Cline MJ. Amplification of human int-2 in breast cancers and squamous carcinomas. Oncogene in breast cancer

16 Cuny M, Kramar A, Courjal F, et al. Relating genotype and phenotype in breast cancer: an analysis of the prognostic significance of amplification at eight different genes or loci and of p53 mutations. Cancer Res 2000;60:1077-83.

17 Robson M, Rajan P, Rosen PP, et al. BRCA-associated breast cancer: absence of a characteristic immunophenotype. Cancer Res 1998;58:1839-42.

18 Noguchi S, Kasugai T, Miki Y, et al. Clinicopathologic analysis of BRCA1- or BRCA2-associated hereditary breast carcinoma in Japanese women. Cancer 1999;85 2200-5.

19 Slamon DJ, Godolphin W, Jones LA, et al. Studies of the HER-2/neu proto-oncogene in human breast and ovarian cancer. Science 1989;244:707-12.
20 Benz CC, Brandt BH, Zanker KS. Gene diagnostics provide new insights into breast cancer prognosis and therapy. Gene 1995;159:3-7.

21 Nagai MA, Pacheco MM, Oshima CT, et al. c-erbB-2 DNA amplification and mRNA expression in human primary breast tumors and its relationship to other prognostic factors. Cancer Biother 1993;8:29-35.

22 Hoang MP, Sahin AA, Ordonez NG, et al. HER-2/neu gene amplification compared with HER-2/neu protein overexpression and interobserver reproducibility in invasive breast carcinoma. Am f Clin Pathol 2000;113:852-9.

23 Tubbs RR, Pettay J, Roche P, et al. Concomitant oncoprotein detection with fluorescence in situ hybridization (CODFISH). A fluorescence-based assay enabling simultaneous visualization of gene amplification and encoded protein expression. $7 \mathrm{Mol}$ Diagn 2000;2:78-83.

24 Janezic SA, Ziogas A, Krumroy LM, et al. Germline BRCA1 alterations in a population-based series of ovarian cancer cases. Hum Mol Genet 1999;8:889-97.

25 Vaziri SAJ, Krumroy LM, Rostai M, et al. Frequency of BRCA1 and BRCA2 mutations in a clinic-based series of breast and ovarian cancer families. Hum Mutat 2001;17:74.

25a Tubbs RR, Pettay JD, Roche PC, et al. Discrepancies in clinical laboratory testing of eligibility for trastuzumab therapy: apparent immunohistochemical false-positives do not get the message. F Clin Oncol 2001;19:27814-21.

26 Breslow NE, International Agency for Research on Cancer. Statistical methods in cancer research. Lyon: International Agency for Research on Cancer, 1980

27 Osin P, Gusterson BA, Philp E, et al. Predicted antioestrogen resistance in BRCA-associated familial breast cancers. Eur f Cancer 1998;34:1683-6.

28 Fantl V, Smith R, Brookes S, et al. Chromosome 11q13 abnormalities in human breast cancer [see comments]. Cancer Surv 1993;18:77-94.

29 Daksis JI, Lu RY, Facchini LM, et al. Myc induces cyclin D1 expression in the absence of de novo protein synthesis and links mitogen-stimulated signal transduction to the cell cycle. Oncogene 1994;9:3635-45.

30 Lee RJ, Albanese C, Fu M, et al. Cyclin D1 is required for transformation by activated Neu and is induced through an E2F-dependent signaling pathway. Mol Cell Biol 2000;20: $672-83$.

31 Lin SY, Xia W, Wang JC, et al. Beta-catenin, a novel prognostic marker for breast cancer: its roles in cyclin D1 expression and cancer progression. Proc Natl Acad Sci US A 2000;97:4262-6.

32 Prall OW, Rogan EM, Sutherland RL. Estrogen regulation of cell cycle progression in breast cancer cells. F Steroid Biochem Mol Biol 1998;65:169-74.

33 Isola J, Chu L, DeVries S, et al. Genetic alterations in ERBB2-amplified breast carcinomas. Clin Cancer Res 1999;5:4140-5.

34 Slamon DJ, Clark GM, Wong SG, et al. Human breast cancer: correlation of relapse and survival with amplification of the HER-2/neu oncogene. Science 1987;235:17782

35 Pauletti G, Godolphin W, Press MF, et al. Detection and quantitation of HER-2/neu gene amplification in human breast cancer archival material using fluorescence in situ hybridization. Oncogene 1996;13:63-72.

36 Tirkkonen M, Johannsson O, Agnarsson BA, et al. Distinct somatic genetic changes associated with tumor progression in carriers of BRCA1 and BRCA2 germ-line mutations. Cancer Res 1997;57:1222-7.

37 Kauraniemi P, Hedenfalk I, Persson K, et al. MYB oncogene amplification in hereditary BRCA1 breast cancer. Cancer Res 2000;60:5323-8. 